\title{
Analytical Predictions for a Natural Spacing within Dyke Swarms
}

\author{
Andrew P. Bunger ${ }^{\mathrm{a}, \mathrm{b}, *}$, Thierry Menand ${ }^{\mathrm{c}, \mathrm{d}, \mathrm{e}}$, Alexander Cruden $^{\mathrm{f}}$, Xi Zhang ${ }^{\mathrm{b}}$, \\ Henry Halls ${ }^{g}$ \\ ${ }^{a}$ Department of Civil and Environmental Engineering, University of Pittsburgh, \\ Pittsburgh, PA, USA \\ ${ }^{b}$ CSIRO Earth Science and Resource Engineering, Melbourne, Australia \\ ${ }^{c}$ Clermont Université, Université Blaise Pascal, Laboratoire Magmas et Volcans, \\ Clermont-Ferrand, France \\ ${ }^{d}$ CNRS, UMR 6524, LMV, Clermont-Ferrand, France \\ ${ }^{e} I R D, R$ 163, LMV, Clermont-Ferrand, France \\ ${ }^{f}$ School of Geosciences, Monash University, Melbourne, Australia \\ ${ }^{g}$ Department of Chemical and Physical Sciences, University of Toronto at Mississauga, \\ Mississauga, Ontario, Canada
}

\begin{abstract}
Dykes often grow next to other dykes, evidenced by the widespread occurrence of dyke swarms that comprise many closely-spaced dykes. In giant dyke swarms, dykes are observed to maintain a finite spacing from their neighbors that is tens to hundreds of times smaller than their length. To date, mechanical models have not been able to clarify whether there exists an optimum, or natural spacing between the dykes. And yet, the existence of a natural spacing is at the heart of why dykes grow in swarms in the first place. Here we present and examine a mechanical model for the horizontal propagation of multiple, closely-spaced blade-like dykes in order to find energetically optimal dyke spacings associated with both constant pressure and constant
\end{abstract}

*710 Benedum Hall, 3700 O'Hara Street, Pittsburgh, PA, 15261, USA

Email address: bunger@pitt.edu (Andrew P. Bunger) 
influx magma sources. We show that the constant pressure source leads to an optimal spacing that is equal to the height of the blade-like dykes. We also show that the constant influx source leads to two candidates for an optimal spacing, one which is expected to be around 0.3 times the dyke height and the other which is expected to be around 2.5 times the dyke height. Comparison with measurements from dyke swarms in Iceland and Canada lend initial support to our predictions, and we conclude that dyke swarms are indeed expected to have a natural spacing between first generation dykes and that this spacing scales with, and is on the order of, the height of the blade-like dykes that comprise the swarm.

Keywords:

dyke swarms, dyke spacing, fluid-driven cracks, hydraulic fractures

\section{1. Introduction}

2 Dykes represent the dominant mode of magma transport through the

3 Earth's lithosphere, and one striking feature is that they often occur as

4 swarms made of several hundreds of individual, sub-parallel dykes originat-

5 ing from apparently a single source region. At the smallest scale, volcanic

6 dyke systems originate from individual magma chambers, such as the Koolau

7 dyke complex, Oahu, in Hawaii (Walker, 1986), the Spanish Peaks, Colorado

8 (Odé, 1957), and the dyke swarms of Iceland (Gudmundsson, 1983; Paquet

9 et al., 2007). At a larger scale, sheeted dyke complexes form an integral part

10 of the crustal structure at mid-ocean ridges. At the largest scale, one finds

11 giant mafic dyke swarms (Figure 1) that extend over hundreds to several 12 thousands of kilometers in length (Ernst and Baragar, 1992). These giant 
structures are found not only on Earth, where they are often associated with continental breakup and flood basalts, but also on Mars and Venus (Halls and Fahrig, 1987; Ernst et al., 2001). The width of these swarms is assumed to reflect the lateral extend of their feeding source, usually thought to be mantle plumes (e.g. Ernst et al., 2001).

Yet, in spite of their ubiquity, dyke swarms have been studied rather descriptively. As a result, field data that could inform about the mechanics and dynamics of dyke swarms remain scarce. The crustal dilation that is induced or accommodated by a swarm is sometimes recorded at different locations within that swarm (e.g. Walker, 1986; Hou et al., 2010), but most field studies record only the strike and dip of the dykes, along with their length and thickness distributions. Length distributions seem to be power-law (e.g. Paquet et al., 2007, and references therein), whereas thickness distributions have been variously described as power-law (e.g. Gudmundsson, 1995), negativeexponential or log-normal (e.g. Jolly and Sanderson, 1995; Jolly et al., 1998). Comparatively, data on dyke spacing are rarely reported. Jolly and Sanderson (1995) demonstrate log-normal distribution of the dyke spacing within the Mull Swarm, Scotland, and from this infer the existence of characteristic length scale that is best described by the median or geometric mean of the spacing. In a similar study, Jolly et al. (1998) examine the geometry of clastic dykes in the Sacramento Valley, California. In this case the authors interpret the dyke spacing to follow a power-law distribution, although it should be noted that their discrimination between power-law and log-normal behavior seems it was not carried out formally but rather relied on visual assessment and is therefore prone to misinterpretation (e.g. Clauset et al., 
2009). Hence, the limited available data provide sufficient motivation to pursue model-derived insight into whether or not a characteristic length scale is expected to exist related to dyke spacing, and if so, what are its physical origins and significance.

The mechanics of dyke propagation and prediction of spacing between cracks in rocks have both received significant attention over the past few decades. On the one hand, the growth of a single dyke has been analyzed in a variety of combinations of geometry and boundary conditions (e.g. Lister, 1990; Mériaux and Jaupart, 1998; Roper and Lister, 2005; Taisne and Jaupart, 2009; Taisne et al., 2011). On the other hand, both analytical (e.g. Hobbs, 1967) and numerical (e.g. Narr and Suppe, 1991; Bai and Pollard, 2000; Olson, 2004) approaches have been applied for the purpose of predicting the spacing between opening mode cracks in layered rocks. But, while there has been a number of mainly industry-driven contributions aimed at understanding crack patterns and driving pressure associated with the growth of multiple hydraulic fractures (e.g. Germanovich et al., 1997; Zhang et al., 2007; Olson, 2008; Jin and Johnson, 2008; Olson and Dahi-Taleghani, 2009; Zhang et al., 2011; Roussel and Sharma, 2011; Bunger et al., 2012; Vermylen and Zoback, 2011; Weng et al., 2011), the issue of optimal spacing between fluid-driven cracks for geometries and boundary conditions that are relevant to dyke propagation has not been addressed.

In this paper we ask whether there is evidence from mechanical analysis that dyke swarms should form with a particular inter-dyke spacing. This question is at the heart of the issue of why dykes should form swarms at all. If mechanical models predict a natural spacing that tends to zero or 
infinity, then it remains fundamentally unclear why there is a widespread morphology wherein many distinct dykes maintain a finite separation over tens to thousands of kilometers of growth.

Whether mechanical analysis can identify a finite characteristic spacing for dyke swarms is not apparent at the outset. There is a temptation to view the problem in terms of fracture mechanics alone. But if we do this, we immediately discover the well-known fact that closely-spaced pressurized cracks exert compressive stresses on each other that reduce the stress intensity that drives the fracturing process (e.g. Benthem and Koiter, 1973). Viewed this way, it is unclear how dykes in a swarm can grow to be a hundred times longer than the spacing between them.

One potential resolution to this issue is to suggest that the dykes must form sequentially, with one dyke propagating after the next to eventually form the observed dyke swarm morphologies. It seems reasonable that this should be a part of the answer. However, crosscutting relationships observed in the field indicate that contemporaneous as well as successive dyke emplacement can be observed within the same swarm (Burchardt et al., 2011). Moreover, the analysis of Bunger (2013) shows that multiple, simultaneously growing fluid-driven cracks can propagate to a length that is much greater than their separation provided that the fluid driving them is sufficiently viscous — which is to say that the energy dissipated in viscous flow greatly exceeds the energy dissipated through breakage of the rock - and provided that their growth in height is constrained so that they are much longer than they are high and hence grow in the well-known blade-like geometry (e.g Perkins and Kern, 1961; Nordgren, 1972; Rubin and Pollard, 1987; 
Lister, 1990; Adachi and Peirce, 2008). Here we examine the mechanical evidence for a natural, or optimal spacing within dyke swarms by extending the method that has been previously developed by Bunger (2013) in order to account for both the asymptotic limits of widely and closely spaced swarms of blade-shaped dykes under both constant pressure and constant influx source conditions.

\section{Dyke Propagation Model}

We consider a model for an array of equally-spaced blade-like dykes that are propagating horizontally through brittle host rock, as sketched in Figure 2. This model is justified for large dyke swarms that grow to be many times greater in length than the thickness of the crust. Examples include the Mackenzie swarm, the Matachewan swarm, the Grenville swarm, and the Abitibi swarm, all in Canada, the Yakust swarm in Siberia, and the Central Atlantic reconstructed swarm (Ernst et al., 1995, and references therein).

For the sake of simplicity, we assume the swarm is characterized by a single spacing $h$ between adjacent dykes (Figure 2), and we investigate how this spacing $h$ affects the propagation of the dykes. In this regard, we neglect the details of the source geometry and the radial propagation of dykes near the source and instead focus on the parallel propagation in a regime that is taken to persist after an early time, source geometry dominated period of growth. Subject to this geometric limitation, details of dyke initiation and early growth wherein the dyke length $R$ is not substantially greater than the height $H$ will not be considered. Practically, the model is valid when $R$ is at least 3 to 5 times greater than $H$ (Adachi and Peirce, 2008). When this is the 


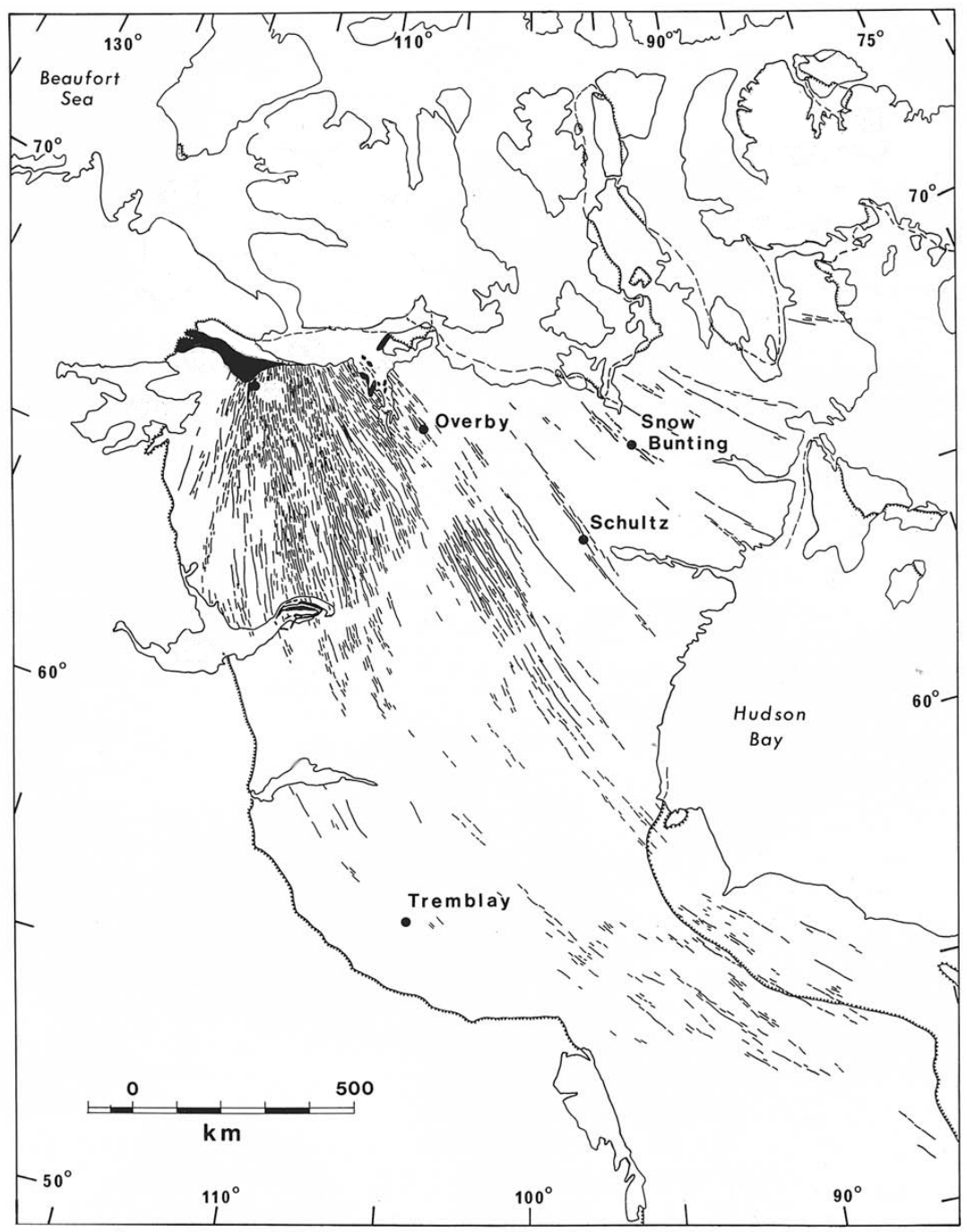

Figure 1: The 1270 Ma giant Mackenzie mafic dyke swarm in the northwestern Canadian Shield (after LeCheminant and Heaman (1989)), whose dykes extend over more than 2,000 $\mathrm{km}$ with an average thickness of $30 \mathrm{~m}$ (Fahrig, 1987). 
case, it is valid to assume (Nordgren, 1972): 1) fluid flow to be unidirectional and along the $x$ direction in Figure 2, that is, parallel to the direction of dyke propagation, and 2) pressure to be uniform within each vertical $y-z$ planar cross section of the hydraulic fracture with the pressure and thickness related according to a local, plane strain condition. The elasticity relation between net pressure $\left(p=p_{f}-\sigma_{o}\right.$ for minimum in situ stress $\sigma_{o}$ and total magma pressure $\left.p_{f}\right)$ and thickness $(w)$ along center line of the dyke $(y=0)$ is thus given by

$$
w(x, t)=\alpha_{1} H \frac{p(x, t)-\sigma_{I}}{E^{\prime}},
$$

where $E^{\prime}=E /\left(1-\nu^{2}\right)$ for Young's modulus $E$ and Poisson's ratio $\nu$, and $\sigma_{I}$ is the compressive stress exerted on the dyke by its neighbors, which is approximated for the widely-spaced case $H \ll h \ll R$ as (Benthem and Koiter, 1973; Bunger, 2013)

$$
\sigma_{I}=p \frac{3 H^{2}}{8 h^{2}}\left(1+O(h / H)^{-2}\right),
$$

where the classical "Big O" notation is used to indicate the limiting behavior of the series. Similarly for the closely spaced case $h \ll H \ll R$ (Supplementary Section 1) the interaction stress is approximated by

$$
\sigma_{I}=p\left(1-\frac{4 h}{H}+O(h / H)^{3}\right) .
$$

${ }_{127}$ Also, $\alpha_{1}(H / h)$ is a factor that accounts for interaction where

$$
\alpha_{1}(H / h) \sim\left\{\begin{array}{cc}
2, & H / h \ll 1 \\
0.35, & H / h \gg 1
\end{array}\right.
$$

with the large spacing limit $(H / h \ll 1)$ readily available from the solution for a single, pressurized crack in plane strain (Sneddon, 1946), and the small 


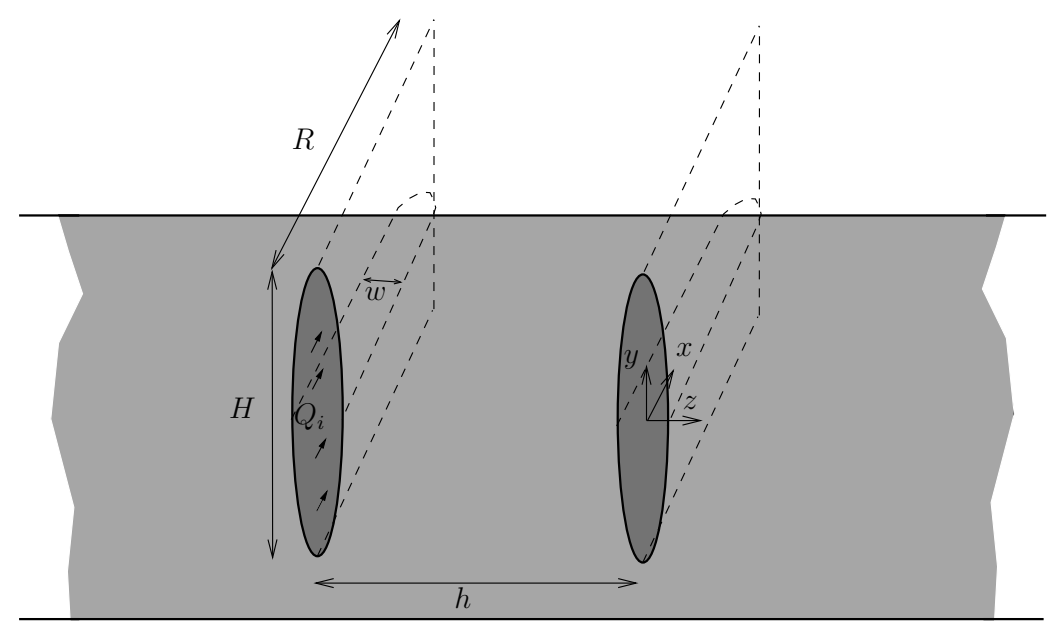

Figure 2: Sketch of the model geometry, showing two members of an infinite array of blade-like dykes.

spacing $(H / h \gg 1)$ limit determined numerically, as detailed in Supplementary Section 2.

Assuming the magma is incompressible, fluid continuity, which comprises the second governing equation, is given by (Nordgren, 1972)

$$
\alpha_{2} H \frac{\partial w}{\partial t}+\frac{\partial q}{\partial x}=0
$$

where $q(x, t)$ is the volume rate of flow through a cross section, once again $w$ is the opening along $y=0$, and $\alpha_{2}(H / h)$ is a factor that behaves like

$$
\alpha_{2}(H / h) \sim \begin{cases}\frac{\pi}{4}, & H / h \ll 1 \\ 1, & H / h \gg 1\end{cases}
$$

with the large spacing limit $(H / h \ll 1)$ arising from the area of an elliptical cross section $(\pi w H / 4)$ and the small spacing $(H / h \gg 1)$ limit coinciding with a rectangular cross-section, which is taken as an approximation of the 
cross section of the dyke in this case, as demonstrated in Supplementary Section 2.

The third governing equation is the Poiseuille equation relating the fluid flux to the fluid pressure gradient. This equation results from solution of the Navier-Stokes equations for laminar flow of a Newtonian fluid subjected to no-slip boundary conditions at the boundaries of the channel and where the thickness of the flow channel is much less than its length. The result is (Nordgren, 1972)

$$
q=-\alpha_{3} \frac{H w^{3}}{\mu^{\prime}} \frac{\partial p}{\partial x},
$$

where $\mu^{\prime}=12 \mu$ and $\mu$ is the dynamic viscosity of the magma, and

$$
\alpha_{3}(H / h) \sim\left\{\begin{array}{cc}
\frac{3 \pi}{16}, & H / h \ll 1 \\
1, & H / h \gg 1
\end{array}\right.
$$

where the large spacing limit $(H / h \ll 1)$ arises from integrating the flux over an elliptical cross section and the small spacing $(H / h \gg 1)$ limit arises from integrating the flux over an approximately rectangular cross section. It should be noted, however, that in the present work we are concerned with orders of magnitude so that what is important is not the precise values of $\alpha_{1}, \alpha_{2}, \alpha_{3}$, but rather that we have confirmed these to be order one.

The leading edge of the dyke requires a condition governing its propagation. However, one of the well-known deficiencies of the approach of Perkins and Kern (1961) and Nordgren (1972) to modeling blade-like hydraulic fractures is that the stresses are not well-defined in the near-tip region, therefore precluding a well-defined propagation condition. A recent asymptotic analysis of the full elasticity equation by Adachi and Peirce (2008) provides a way 
forward, however a fluid-driven blade-like crack model has yet to be developed. But a lack of such a model is not important for our analysis provided that we assume that the energy dissipated by flow of the viscous fluid is much larger than the energy that is dissipated by rock fracture (after e.g. Lister, 1990; Lister and Kerr, 1991). It follows that if we are in viscosity dominated conditions, the scaling and energy relations that are subsequently derived will not depend on this moving boundary condition at the dyke tip.

Finally, assuming that the behavior for $R \gg H$ (long blade-like dykes) does not depend on the details of the initial conditions, these can be neglected for now. The system of equations is thus completed by homogeneous boundary conditions on the thickness and magma flux at the leading edge

$$
x=R: \quad w=0, \quad q=0 .
$$

and the magma source condition, which is discussed in the following section.

\section{Magma Source Condition}

The source is idealized as a time varying volume of magma $(V(t))$ that is characterized by a compressibility $C_{m}$ that describes the change in pressure associated with a given change in stored magma volume. The source is overpressurized relative to the minimum component of the in situ stress $\sigma_{o}$ by a time dependent amount

$$
p_{o}(t)=p_{o}(0)+\frac{V_{r}(t)-V_{d}(t)}{V(0) C_{m}} .
$$

Hence, $p_{o}(0)$ and $V(0)$ are the source overpressure and volume at the start of dyke growth and $V_{d}$ and $V_{r}$ are the total volume injected into dykes and 
added to the source region through recharge processes, respectively. Giant dyke swarms are usually thought to be fed by mantle plumes (Ernst et al., 2001), and so the recharge processes envisaged here would be the supply of magma from the tail to the head of these mantle plumes.

The total volume is thus given by $V(t)=V(0)+V_{r}(t)-V_{d}(t)$. Letting $Q(t)=q(0, t)$ be the volumetric flow rate out of the source and into the dykes, and $Q_{r}(t)$ be the recharge rate of the source region, we have

$$
p_{o}(t)=p_{o}(0)+\frac{1}{V(0) C_{m}} \int_{0}^{t}\left(Q_{r}-Q\right) \mathrm{d} t .
$$

This description of the source leads naturally to consideration of two limiting cases. The first is for an infinitely large and compressible source, where we are left with a constant pressure condition

$$
x=0: \quad p=p_{0}=p_{o}(0), \quad V(0) C_{m} \rightarrow \infty .
$$

Obviously, for $Q_{r} \neq Q$, this boundary condition is associated with time being sufficiently small so that the second term on the right hand side of Eq. (8) vanishes relative to $p_{0}$.

On the other hand, the small, incompressible source limit is most clearly represented by differentiating Eq. (8) with respect to time to obtain

$$
Q=Q_{r}-V(0) C_{m} \frac{\mathrm{d} p_{o}(t)}{\mathrm{d} t}
$$

where it is clear, then, that the source boundary condition is

$$
x=0: \quad q=Q_{r}, \quad V(0) C_{m} \rightarrow 0,
$$

196 which is a condition of constant influx if we further assume $Q_{r}(t)=Q_{o}$, a constant. Furthermore, it is apparent from Eq. (10) that the constant 
influx condition is associated with large time if $\mathrm{d} p_{o} / \mathrm{d} t$ decays with time - for example if $p_{o} \sim t^{b}$ for $b<1$.

We note, however, that dyke flow rates $Q$ are usually several orders of magnitude greater than their source recharge rates $Q_{r}$. For instance, studies of long-term magma supply rate at Kilauea, Hawaii (Swanson, 1972) and Krafla, Iceland (Johnsen et al., 1980) give $Q_{r} \sim 1-5 \mathrm{~m}^{3} \mathrm{~s}^{-1}$. Estimates of dyke flow velocities are in the range $0.1-1 \mathrm{~m} / \mathrm{s}$ (Brandsdóttir and Einarsson, 1979; Peltier et al., 2007; Ayele et al., 2009; White et al., 2011), which would amount to average volumetric flow rates $Q \sim 10^{2}-10^{4} \mathrm{~m}^{3} \mathrm{~s}^{-1}$ for horizontally propagating dykes that are $1 \mathrm{~m}$ wide and $1-10 \mathrm{~km}$ high. This range of values reflects the requirement that dykes need to propagate fast enough through the Earth's crust to avoid death by solidification: continued magma flow in dykes requires a minimum dyke width hence magma flow rate for the advective supply of heat by flowing magma to be able to offset the heat conducted away by the colder host rocks (Bruce and Huppert, 1989; Petford et al., 1993). This range of values agrees with the volumetric flow rates estimated for the 1783-1785 Laki eruption in Iceland $\left(100-9000 \mathrm{~m}^{3} \mathrm{~s}^{-1}\right.$, Thordarson and Self, 1993), the magmatic activity in Hawaii in the 1970s $\left(1-700 \mathrm{~m}^{3}\right.$ $\mathrm{s}^{-1}$, Wright and Tilling, 1980; Duffield et al., 1982), the September 1984 eruption of Krafla, Iceland $\left(10-10^{3} \mathrm{~m}^{3} \mathrm{~s}^{-1}\right.$, Tryggvason, 1986), or the 2003 magmatic activity at Piton de la Fournaise, Réunion Island $\left(10-700 \mathrm{~m}^{3}\right.$ $\mathrm{s}^{-1}$, Peltier et al., 2007). Some of these volumetric-flow-rate estimates are eruption rates and are observed to decline with time, whereas dyke intrusions might involve more constant rates (e.g. Peltier et al., 2007; Traversa et al., 2010). Moreover, one could argue that volumetric flow rates $Q$ for giant 
dyke swarms would be even greater than these reported values due to the larger average thickness of their dykes. This being the case, $Q$ would have to be derived mainly from the stored volume, hence the infinitely large and compressible source, Eq. (9) is probably applicable to many, if not most, dyke swarms.

\section{Energy Considerations}

For a compressible magma source, the elastic strain energy $(\mathcal{E})$ is increased by the work done on the magma source by the recharge $\left(W_{r}\right)$ and work done on the source by the in situ stress $\left(W_{\text {so }}\right)$, and it is decreased by the work done by the magma source on the array of dykes $\left(W_{d f}\right)$. Energy conservation thus requires

$$
\dot{\mathcal{E}}=\dot{W}_{r}+\dot{W}_{s o}-\dot{W}_{d f},
$$

where the overdot indicates the time derivative and, following Lecampion and Detournay (2007), it is easy to show that $\dot{W}_{r}=Q_{r} p_{f}, \dot{W}_{d f}=Q p_{f}$, and $\dot{W}_{s o}=\sigma_{o}\left(Q-Q_{r}\right)$. Hence

$$
\dot{\mathcal{E}}=\left(Q_{r}-Q\right) p
$$

For the infinitely compressible source, that is, when $p=p_{0}$ at the inlet according to Eq. (9), maximizing the rate of decrease in stored elastic energy in the magma source corresponds to maximizing $Q$ (when $Q_{r}$ is a constant). The first of two energy conjectures, then, is that dyke systems associated with infinitely compressible sources will energetically favor configurations that maximize $-\dot{\mathcal{E}}$, and therefore growth geometry that maximizes the magma 
influx rate to the dykes $Q$ will be considered advantageous. What's more, if $Q_{r} \ll Q$, as indicated by field data, we have $-\dot{\mathcal{E}} \sim Q p$ so that it makes sense to focus on quantifying what we will call the "net dyke propagation work rate", $\dot{W}_{d}=Q p$.

On the other hand, for an incompressible source, fluid can neither be stored nor mobilized from storage, hence $Q=Q_{r}$ (Eq. 11). So it is obvious that $\dot{\mathcal{E}} \equiv 0$ and therefore we cannot consider the change in strain energy of the source as we did when it was compressible. In this case, we follow Bunger (2013) and consider the rate of work done on the dykes $\dot{W}_{d f}=Q p_{f}$. The second energy conjecture is that dyke swarms associated with incompressible sources will energetically favor configurations that minimize $\dot{W}_{d f}$, and therefore growth geometry that minimizes the pressure required to drive growth at a fixed rate of influx $\left(Q(t)=Q_{o}\right)$ will be considered advantageous. Furthermore, when the in situ stress $\sigma_{o}$ is a constant, the minimum of $\dot{W}_{d f}$ coincides with the minimum of $\dot{W}_{d}=Q p$, so that once again it is sensible to focus on quantifying the dyke propagation work rate, $\dot{W}_{d}$.

Ongoing studies are required to better understand the conditions under which these conjectures are valid. When the overall geometry of a dyke swarm is relatively simple, they seem reasonable. However, when the dyke patterns become more complicated, the energy conjectures may not always hold. For example, mine-through mapping of hydraulic fracture growth through rock masses that contain natural fractures has shown the hydraulic fracture path can offset as it grows through some of the discontinuities so that the final fracture is not planar, but rather follows a stair-like morphology (Jeffrey et al., 2009). The available 2D modeling (Jeffrey et al., 2009) shows that 
these offsets lead to an increase in the wellbore pressure relative to the case of planar growth for a given injection rate. This implies that the pattern of hydraulic fracture growth does not always result in a final configuration that would be predicted from global, equilibrium energy considerations. Instead, the morphology, or pattern of hydraulic fractures, appears to be determined by local interaction laws that determine the evolution of the system to attain a final configuration that cannot in general be predicted from simply considering global, equilibrium energy minimization.

These caveats aside, it is prudent to investigate a relatively simple dyke swarm geometry as a starting point from which we can understand if, in fact, the mathematical model implies the existence of an energetically optimal spacing between the dykes and to determine how this spacing depends on the nature of the source.

\section{Approximating the Energy Rate}

We consider a uniform array of blade-like dykes originating from the same source and maintaining a constant spacing and equal lengths as they grow. In the absence of a fully coupled model that accounts for all of the mechanical interactions among the dykes, a straightforward method for estimating the "input power" $\dot{W}_{d}$ based on scaling relationships can be used. Following Bunger (2013), the input power required to propagate a swarm of $N$ growing dykes can be expressed as

$$
\dot{W}_{d}=\sum_{i=1}^{N} \dot{W}^{(i)}, \quad \dot{W}^{(i)}=\dot{U}^{(i)}-\dot{W}_{I}^{(i)}+D_{c}^{(i)}+D_{f}^{(i)}
$$


Which is to say that the input power to each dyke increases the strain energy in the host rock $\dot{U}^{(i)}$, overcomes the work that is done on that dyke by the stresses induced by the others $\dot{W}_{I}^{(i)}$, or is dissipated either through rock fracture $D_{c}^{(i)}$ or viscous flow of the magma $D_{f}^{(i)}$. Recalling that our consideration is limited here to viscosity dominated hydraulic fractures, we only consider cases wherein $D_{c}^{(i)} \ll D_{f}^{(i)}$. Hence the contribution of $D_{c}^{(i)}$ to Eq. (14) can be neglected for the present study (see Bunger (2013) for a more thorough discussion).

For the case of a uniform array of dykes that are at the onset of interaction such that $h \gg H$, Bunger (2013) shows that

$$
\begin{aligned}
& \dot{U}^{(i)} \approx \frac{L P X H}{t}, \quad \dot{W}_{I}^{(i)} \approx-\frac{L P X H}{t}\left(\frac{H^{2}}{h^{2}}+O(H / h)^{4}\right), \\
& D_{f}^{(i)} \approx \frac{X^{3} P^{2} H}{L \mu^{\prime}}\left(1+\frac{H^{2}}{h^{2}}+O(H / h)^{4}\right) .
\end{aligned}
$$

Here $L, P$, and $X$ are characteristic quantities that estimate the dyke length, the magma over pressure, and the dyke thickness, respectively. The form of Eq. (15), then, clearly shows that $\dot{W}_{I}^{(i)}$ is negligible as $h / H \rightarrow \infty$, that is, for very widely spaced dykes, and its importance is greater for smaller dyke spacing. Before moving on to obtain $\{L, P, X\}$ from the governing equations, let us also present the approximations for the terms in Eq. (14) for the case of closely spaced dykes $(h \ll H)$,

$$
\begin{aligned}
& \dot{U}^{(i)} \approx \frac{L P X H}{t}, \quad \dot{W}_{I}^{(i)} \approx-\frac{L P X H}{t}\left(1+\frac{h}{H}+O(h / H)^{2}\right), \\
& D_{f}^{(i)} \approx \frac{X^{3} P^{2} H}{L \mu^{\prime}}\left(1+\frac{h}{H}+O(h / H)^{2}\right) .
\end{aligned}
$$

The governing equations (Eqs. 1-11) directly lead to appropriate expressions for $L, P$, and $X$. A useful technique (after Detournay (2004)) is to 
substitute

$$
w=X \Omega, \quad p=P \Pi, \quad R=L \gamma,
$$

whereupon the objective becomes to define $\{X, P, L\}$ such that the dimensionless quantities $\{\Omega, \Pi, \gamma\}$ are all of order one $(O(1))$. For example, in the case of an infinitely compressible source with widely-spaced dykes, the inlet boundary condition (Eq. 9) tells us that $\Pi=O(1)$ if we take $P=p_{0}$. Then, substituting into the elasticity equation (Eq. 1), we can ensure that $O(\Omega)=O(\Pi)$ (and hence $\Omega=O(1)$ ) by taking $X=H P / E^{\prime}$. Finally, the characteristic dyke length is obtained by first substituting the Poiseuille equation (Eq. 5) into the continuity equation (Eq. 4) along with aforementioned values of $P$ and $X$. The characteristic length $L$ is then chosen so that the two terms of the continuity equation are guaranteed to be of the same order, which is to set the group of parameters that appears after the substitution to one. The result is $L=H p_{0}^{3 / 2} t^{1 / 2} /\left(E^{\prime} \mu^{\prime 1 / 2}\right)$.

The procedure can be repeated for each of the four limiting regimes that come from the widely and closely spaced limits for infinitely compressible and incompressible sources, respectively. This scaling procedure is both straightforward and it has been discussed at length in a number of prior contributions (see Detournay (2004) for a review), hence the details are omitted. The resulting characteristic quantities are summarized in Table 1. Substituting these quantities into the appropriate choice of Eq. (15) or (16) and summing according to Eq. (14) provides a rapid way of estimating the total input power required to sustain the growth of a swarm of dykes. 


\begin{tabular}{ccccc} 
Source Condition & Spacing & $X$ & $P$ & $L$ \\
\hline$p=p_{0}$ & $h \gg H$ & $\frac{H p_{0}}{E^{\prime}}$ & $p_{0}$ & $\frac{H p_{0}^{3 / 2} t^{1 / 2}}{E^{\prime} \mu^{\prime 1 / 2}}$ \\
$p=p_{0}$ & $h \ll H$ & $\frac{h p_{0}}{E^{\prime}}$ & $p_{0}$ & $\frac{h p_{0}^{3 / 2} t^{1 / 2}}{E^{\prime} \mu^{\prime 1 / 2}}$ \\
$q=Q_{o}$ & $h \gg H$ & $\left(\frac{Q_{i}^{2} \mu^{\prime} t}{E^{\prime} H}\right)^{1 / 5}$ & $\left(\frac{E^{\prime 4} Q_{i}^{2} \mu^{\prime} t}{H^{6}}\right)^{1 / 5}$ & $\left(\frac{E^{\prime} Q_{i}^{3} t^{4}}{H^{4} \mu^{\prime}}\right)^{1 / 5}$ \\
$q=Q_{o}$ & $h \ll H$ & $\left(\frac{h Q_{i}^{2} \mu^{\prime} t}{E^{\prime} H^{2}}\right)^{1 / 5}$ & $\left(\frac{E^{\prime 4} Q_{i}^{2} \mu^{\prime} t}{h^{4} H^{2}}\right)^{1 / 5}$ & $\left(\frac{E^{\prime} Q_{i}^{3} t^{4}}{h H^{3} \mu^{\prime}}\right)^{1 / 5}$
\end{tabular}

Table 1: Scaling factors that estimate the dyke thickness $X$, magma net pressure $P$, and dyke length $L$ for the four limiting regimes, where the $q=Q_{o}, h \gg H$ case comes from Nordgren (1972).

\section{Constant Pressure Limit}

For the constant inlet pressure limiting case the applicable energy conjecture is that the dyke configuration that maximizes the rate of work done by the magma source on the dyke swarm will be energetically advantageous (Section 4). By this statement, searching for an optimum spacing between the dykes is synonymous with searching for a spacing that maximizes $\dot{W}_{d}$ (Eq. 14).

Because we are limiting consideration to a uniform array of dykes, the summation in Eq. (14) can be expressed simply as $\dot{W}_{d}=N \dot{W}^{(i)}$, where $\dot{W}^{(i)}$ is the input power required to propagate one dyke in the array. Furthermore, it is not physically reasonable to let the width of the swarm grow unconstrained as would be the case if $h$ and $N$ were both unconstrained. Rather, natural dyke swarms are usually observed to cover a zone of some finite width (Halls and Fahrig, 1987; Ernst et al., 2001; Paquet et al., 2007). For example, this finite width, $Z$, can be considered to be on the order of the lateral extent of the magmatic source feeding the swarm. This being the 
case, the swarm width $Z$, the number of dykes $N$, and their spacing $h$ are related as $h=Z /(N-1)$, which for $N \gg 1$ can be approximated as $h \approx Z / N$, so that $\dot{W}_{d} \approx(Z / h) \dot{W}^{(i)}$. Taking the approximations from Eq. (15) and characteristic quantities from Table 1, the input power for the widely-spaced $(h \gg H)$ regime is

$$
\dot{W}_{d} \approx \frac{H^{3} p_{0}^{7 / 2} Z}{h E^{\prime 2} \mu^{\prime 1 / 2} t^{1 / 2}}\left(1+O(H / h)^{2}\right) .
$$

On the other hand, for the closely-spaced $(h \ll H)$ regime, the approximations from Eq. (16) lead to

$$
\dot{W}_{d} \approx \frac{h H p_{0}^{7 / 2} Z}{E^{\prime 2} \mu^{1 / 2} t^{1 / 2}}(1+O(h / H)) .
$$

These two expressions hold a number of important insights regarding the behavior of the problem under consideration. Firstly we can see that $\dot{W}_{d}$ decreases with time for a fixed initial number of dykes $N_{0}$. This is an intriguing result because it means that at some time it will be advantageous, that is, in the sense of causing an increase in $\dot{W}_{d}$, to initiate new dykes in the spaces between the initial dykes. And after some time with these two generations of dykes growing, it could become advantageous again to initiate a third generation of dykes growing in the spaces between the existing dykes.

It is important to realize, then, that field observations, especially in the vicinity of the source, can be expected to show a dyke spacing that is less than the predictions from our analysis. Also, calculations of median or mean dyke spacings across an entire swarm will be smaller than what is predicted here. So to summarize: 1) the subsequent analysis in this paper provides an estimate of the spacing between dykes in the first generation, and 2) 
the dependence of $\dot{W}_{d}$ on $t$ as shown in Eqs. (18) and (19) suggests that subsequent generations can be expected to form leading to hierarchical sets of dykes within the swarm. Clearly a simulator of dyke swarm growth that is able to capture this complex behavior, and especially the point at which the system prefers to initiate new, infilling dykes rather than to continue growing the original array of dykes, would be a highly valuable tool for further investigation of this anticipated phenomenon.

It is also useful to identify a characteristic work rate $\left(\dot{W}_{d}^{*}\right)$ that emerges when $h \approx H$ given by

$$
\dot{W}_{d}^{*}=\frac{H^{2} p_{0}^{7 / 2} Z}{E^{\prime 2} \mu^{\prime 1 / 2} t^{1 / 2}}
$$

Recalling that $\dot{W}_{d} \approx p_{0} Q$, we can therefore estimate the total rate of influx to the swarm from the magma source when $h \approx H$ as

$$
Q \approx \frac{H^{2} p_{0}^{5 / 2} Z}{E^{\prime 2} \mu^{\prime 1 / 2} t^{1 / 2}}, \quad h \approx H .
$$

By integrating $Q$ with respect to time we can obtain an estimate of the volume of the swarm, $V$, given by

$$
V \approx \frac{H^{2} p_{0}^{5 / 2} Z t^{1 / 2}}{E^{\prime 2} \mu^{\prime / 2}}, \quad h \approx H
$$

Note that the factor of 2 that arises from the integration of $Q$ has been dropped because it is spurious in light of the fact that these quantities are intended to estimate order of magnitude, not to provide precise predictions. Most importantly, though, Eqs. (18) and (19) provide insight into the dependence of $\dot{W}_{d}$ on the spacing $h$. As a visual approach, we have normalized both expressions by $\dot{W}_{d}^{*}$ (Eq. 20) and plotted the resulting normalized input 


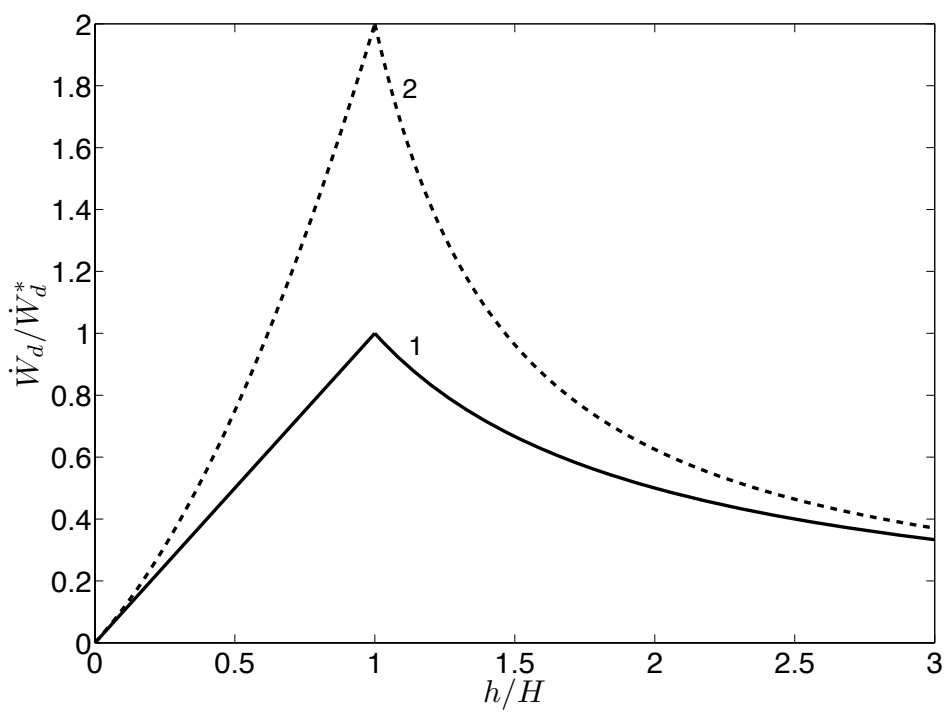

Figure 3: Normalized input power $\dot{W}_{d}$ to the dyke swarm for the case of constant pressure at the source, where the numerical label indicates the number of terms retained in the asymptotic series.

power as a function of $h / H$ in Figure 3. This result, and indeed direct inspection of Eqs. (18) and (19), shows that $\dot{W}_{d}$ increases with decreasing $h$ for $h \gg H$ and decreases for decreasing $h$ for $h \ll H$, with suggestion of a sharp peak at $h \approx H$. Therefore, we conclude that a dyke swarm that is driven by a constant pressure source will have an optimum (first generation) dyke spacing of $h \approx H$.

\section{Constant Influx Limit}

For the constant influx limiting case the applicable energy conjecture is that the dyke configuration that minimizes the rate of work done by the magma source on the dyke swarm will be energetically advantageous (Section 
4). By this statement, searching for an optimum spacing between the dykes is synonymous with searching for a spacing that minimizes $\dot{W}_{d}$ (Eq. 14). Also we recall that the constant influx limit is probably not as widely applicable to dyke swarms as the constant pressure limit (Section 3).

Nonetheless, for the limiting case of constant total influx $Q_{o}$ that is partitioned equally among all of the dykes, the approximations from Eq. (15) and characteristic quantities from Table 1 lead to an estimate for the input power for the widely-spaced $(h \gg H)$ regime as

$$
\dot{W}_{d} \approx\left(\frac{h^{2} E^{\prime 4} \mu^{\prime} Q_{o}^{7} t}{H^{6} Z^{2}}\right)^{1 / 5}\left(1+O(H / h)^{2}\right) .
$$

On the other hand, for the closely-spaced $(h \ll H)$ regime, the approximations from Eq. (16) lead to

$$
\dot{W}_{d} \approx\left(\frac{E^{\prime 4} \mu^{\prime} Q_{o}^{7} t}{h^{2} H^{2} Z^{2}}\right)^{1 / 5}(1+O(h / H)) .
$$

To leading order $\dot{W}_{d} \approx Q_{o} P$ in both cases, with $P$ from Table 1 . And so we see that $P$, and hence $\dot{W}_{d}$, increases with time. Recalling that the energy conjecture for the constant influx case is that the system will favor configurations that minimize $\dot{W}_{d}$, this increasing behavior with time once again opens the possibility that subsequent generations of dykes could be initiated in the spaces between the primary dykes.

As in the case of the constant pressure source, the most interesting implication of Eqs. (23) and (24) has to do with the spacing that optimizes (in this case minimizes) $\dot{W}_{d}$. And here we have a somewhat more complicated situation than for the constant pressure source. By introducing and 
normalizing by a characteristic power

$$
\dot{W}_{d}^{*}=\left(\frac{E^{\prime 4} \mu^{\prime} Q_{o}^{7} t}{H^{4} Z^{2}}\right)^{1 / 5},
$$

it is apparent that for the constant pressure source, the leading order term of the widely-spaced approximation (Eq. 18) goes like $H / h$ with subsequent terms going like $(h / H)^{1-2 n}$ for $n=1,2, \ldots$. Which is to say that the leading order term and all subsequent correction terms show $\dot{W}_{d}$ increases with decreasing $h / H$. The converse is true for the closely-spaced approximation (Eq. 19), with the important point being that the leading order term and all subsequent correction terms in the series indicate that $\dot{W}_{d}$ decreases with decreasing $h$. This shows that both expansions can be pushed all the way to $h=H$ without a change in the sign of the derivative of $\dot{W}_{d}$ with respect to $h / H$.

The behavior of both series is fundamentally different for the constant influx limiting case. Starting with the widely-spaced approximation (Eq. $23)$, we see that the leading order term of the series goes like $(h / H)^{2 / 5}$. But the next term in the series goes like $(h / H)^{-8 / 5}$ with subsequent terms going like $(h / H)^{(-10 n+2) / 5}$ for $n=2,3, \ldots$ So the leading order term indicates that $\dot{W}_{d}$ decreases (which is considered advantageous in this case) with decreasing $h / H$ for $h \gg H$. However, as $h \rightarrow H$ the subsequent terms in the series become important and will at some point change the sign of $\mathrm{d} \dot{W}_{d} / \mathrm{d}(h / H)$. The situation is similar for the closely-spaced approximation (Eq. 24), so that we also expect the sign of $\mathrm{d} \dot{W}_{d} / \mathrm{d}(h / H)$ to change in the range $0<h / H<1$. Figure 4 shows the behavior of both the widely and closely spaced approximations of $\dot{W}_{d}$ (Eqs. 23 and 24), normalized by the characteristic power $\dot{W}_{d}^{*}$. Four curves are graphed for each approximation. These are labeled with 


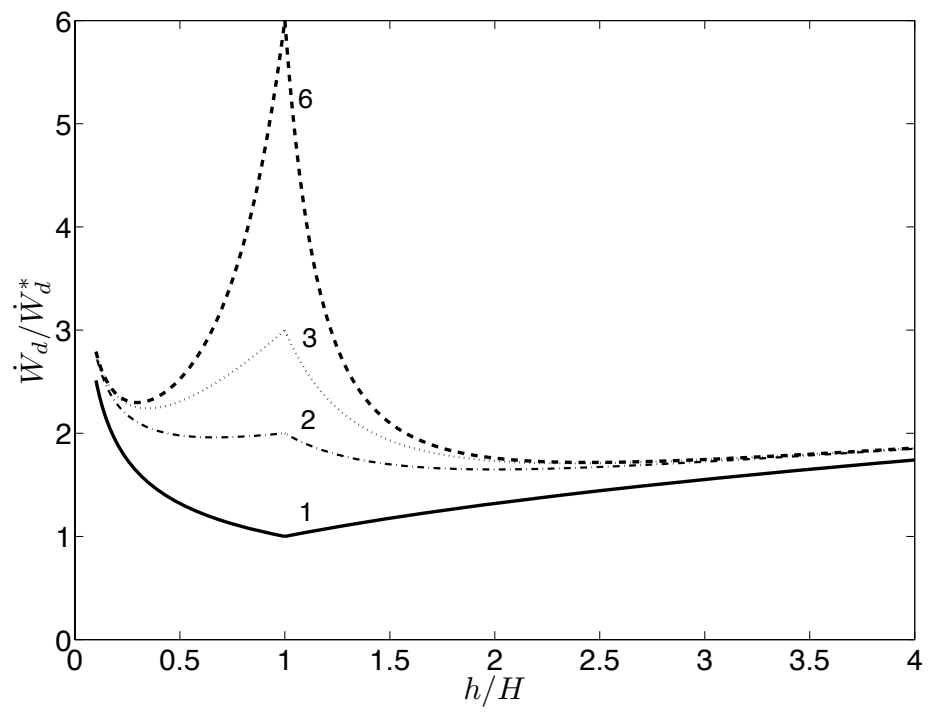

Figure 4: Normalized input power $\dot{W}_{d}$ to the dyke swarm for the case of constant influx from the source, where the numerical label indicates the number of terms retained in the asymptotic series. 
a number that indicates the number of terms $(M+1)$ retained in the series $\dot{W}_{d} / \dot{W}_{d}^{*} \approx \sum_{n=0}^{M}(h / H)^{(-10 n+2) / 5}$ corresponding to Eq. (23), or the series $\dot{W}_{d} / \dot{W}_{d}^{*} \approx \sum_{n=0}^{M}(h / H)^{(5 n-2) / 5}$ corresponding to Eq. (24). Per the relevant energy conjecture (Section 4), in this case we are looking for minima rather than maxima in these curves and, as expected we observe two local minima, one in the range $0<h / H<1$ and one for $h / H>1$.

It is important to be clear that Figure 4 represents an approximation to the behavior of $\dot{W}_{d}$. From it we can see clearly that the model predicts two local minima and we can be confident that they will be $O(1)$ and in the ranges $0<h / H<1$ and $h / H>1$. However, we cannot precisely predict the values of $h / H$ that minimize $\dot{W}_{d}$ nor can we be sure which of the local minima will be the global minimum. This is because the actual large and small $h / H$ expansions embodied in Eqs. (23) and (24) have the form $\dot{W}_{d} / \dot{W}_{d}^{*} \approx \sum_{n=0}^{M} a_{n}(h / H)^{(-10 n+2) / 5}$ and $\dot{W}_{d} / \dot{W}_{d}^{*} \approx \sum_{n=0}^{M} b_{n}(h / H)^{(5 n-2) / 5}$, respectively, where $a_{n}$ and $b_{n}$ are $O(1)$ quantities that must be determined from a solution to the governing equations (Eqs. 1-11) that enables computation of the energy integrals defined by Bunger (2013) (for example see Supplementary Section 3). Here we have simply taken $a_{n}=1$ and $b_{n}=1$. In this coarse approximation, the widely-spaced local minimum appears as the global minimum, and its location is $h / H=2$ for the 2 term series and it moves towards $h / H \approx 2.5$ when many terms are included in the series. On the other hand, the location of the closely spaced local minimum is $h / H=2 / 3$ for the 2 term series and it moves towards $h / H \approx 0.3$ when many terms are included in the series.

The striking conclusion is that there exist two local minima in the input 
power $\dot{W}_{d}$, both of which could represent optimal spacings for dyke growth under conditions of constant influx (if indeed the constant influx condition is relevant to some field cases). Further analysis is required to pinpoint the locations of the minima, but we roughly expect them to be around $h / H \approx 2.5$ and $h / H \approx 0.3$. Further analysis is also required to determine which of these is the global minimum.

\section{Field Comparisons}

Our model predicts the optimal first-generation dyke-spacing that dyke swarms will tend to develop. By "first-generation" we mean the spacing of the first set of dykes that grow into the host rock. These will naturally arrest at some point and additional dykes will fill in between them. However, we expect from this model, based on the constant pressure inlet conditions (as argued in Section 3), that the first-generation will be the thickest dykes and these will have a spacing that is commensurate with the dyke height $H$. The model provides also an estimate of how the volume of the swarm will increase with time (Eq. 22). Both predictions can be tested against field observations.

\subsection{Iceland}

We first devote our attention to the magmatic activity that took place at Krafla in the late 1970s, and to the Tertiary Alftafjördur dyke swarm in eastern Iceland.

According to Sigurdsson (1987), the Krafla rifting episode involved the repeated horizontal injection of fairly similar dykes, whose height ranged between $2 \mathrm{~km}$ and $5 \mathrm{~km}$ (with an average of $2.8 \mathrm{~km}$ ) and which propagated at an average velocity of $0.5 \mathrm{~m} / \mathrm{s}$ over distances of $10 \mathrm{~km}$ to $30 \mathrm{~km}$ from a 
magmatic source with an estimated overpressure of about $10 \mathrm{MPa}$. The total volume of magma that was evacuated from the magma chamber during the whole event has been estimated to be $1-2 \mathrm{~km}^{3}$ (Sigurdsson, 1987).

Eq. (22) provides an estimate of a dyke-swarm volume as a function of time. Conversely, we can use this equation to estimate the time required to emplace a swarm of a particular volume. Taking the average values provided by Sigurdsson (1987) along with a dyke swarm width of $10 \mathrm{~km}$, values for the Young's modulus $E=10 \mathrm{GPa}$ and the Poisson's ratio $\nu=0.25$, and assuming a magma viscosity of $100 \mathrm{~Pa} \mathrm{~s}$, Eq. (22) predicts an injection duration for a $1-\mathrm{km}^{3}$ dyke swarm of about $7 \mathrm{~h}$. This is in the same order of magnitude as the duration of dyke injections at Krafla, which was estimated to last about $25 \mathrm{~h}$ based on the monitoring of their seismic activity (Sigurdsson, 1987).

Paquet et al. (2007) studied the Tertiary Alftafjördur dyke swarm in Eastern Iceland where they measured the dyke-thickness distribution within the swarm at two different locations. They observed a clustering of dykes with a characteristic spacing of $1.5 \mathrm{~km}$ to $2.5 \mathrm{~km}$, which seems to have been determined visually. Additionally, a Fast Fourier Transform analysis gives a mode of $2.5 \mathrm{~km}$. Importantly, these spacing values are reported to correspond to the distribution of the thickest dykes, which would reflect the first generation of dykes and hence those we expect to be consistent with our model. If one takes the average dike height given by Sigurdsson (1987) at Krafla of 2.8 $\mathrm{km}$ as representative of horizontally-propagating dykes throughout Iceland, then the study of Paquet et al. (2007) suggests that the Tertiary Alftafjördur dyke swarm developed a characteristic dyke-spacing comparable to the average height of its dykes, as suggested by our model. 


\subsection{Canada}

In crustal-scale giant radiating dyke swarms (Halls and Fahrig, 1987) it is reasonable to assume that individual dykes traverse the entire thickness of the crust $(H \approx 30-40 \mathrm{~km})$ or a significant portion of the crust. Here we focus on constraining the spacing of first-generation dykes in the 1270 Ma Mackenzie (Figure 1) and the 2470-2450 Ma Matachewan dyke swarms, Canada.

Dykes in the Mackenzie swarm converge towards a common origin, attributed to the head of the mantle plume that supplied magma to the dykes, north of Coppermine in the Canadian Arctic archipelago (Figure 1). The swarm radiates across the northern half of the Canadian Shield with a fan angle close to the origin of 100 degrees, covering an area of $2.1 \times 10^{6} \mathrm{~km}^{2}$ and extending up to 2,400 km along strike (Ernst and Buchan, 2001). In more distal southeastern parts of the swarm, $>1000 \mathrm{~km}$ from the origin, the dyke pattern is more linear and attributed to a transition from propagation within a radial plume-related stress regime to a regional stress regime (Ernst and Buchan, 2001; Hou et al., 2010). Magnetic fabric analysis indicates a second transition from vertical to horizontal magma flow regimes occurring 500-600 $\mathrm{km}$ from the swarm center, probably associated with the outer boundary of the plume head (Ernst and Baragar, 1992). Mackenzie dykes range in thickness from $1 \mathrm{~m}$ to $150 \mathrm{~m}$, with a mean of $30 \mathrm{~m}$ (Fahrig, 1987). The mean thickness increases from $\sim 18 \mathrm{~m}, 400 \mathrm{~km}$ from the swarm center to $\sim 33 \mathrm{~m}$ more than $600 \mathrm{~km}$ out (Baragar et al., 1996). Likewise, the mean spacing between dykes increases from $\sim 6.7 \mathrm{~km}$ about $500 \mathrm{~km}$ from the swarm center to $\sim 25 \mathrm{~km}$ approximately $2100 \mathrm{~km}$ to the southeast in northwestern Ontario (Hou et al., 2010). A recent compilation of Proterozoic intrusions in 
northwest Ontario confirms the mean spacing of distal Mackenzie dykes to be $27 \mathrm{~km}$ with a range from 7.8 to $93 \mathrm{~km}$ (Stott and Josey, 2009). However, spacing between the most continuous dykes is typically between 35 and 65 $\mathrm{km}$.

The systematic outward increase in both mean dyke thickness and spacing from the swarm center can be explained by a corresponding decrease in the number of second- and higher-generation dykes. We therefore suggest that the thickness and spacing of Mackenzie dykes at the distal fringes of the swarm in northwestern Ontario are characteristic of the first-generation dykes. Assuming the dykes propagated horizontally over a height approximately equal to the thickness of the crust then $h \approx H$, in agreement with the model prediction under the constant pressure inlet condition.

The 2490-2450 Ma Matachawan dyke swarm of central Ontario is well characterized by aeromagnetic mapping, and paleomagnetic, geochemical, geochronological and petrologic studies (West and Ernst, 1991; Bates and Halls, 1991; Halls et al., 1994; Percival et al., 1994; Phinney and Halls, 2001). The Matachewan swarm fans northwards from a center located in Lake Huron and covers an area of $250,000 \mathrm{~km}^{2}$ (Halls et al., 1994). Dykes can be traced for more than $1000 \mathrm{~km}$ northwards from the center across a fan angle of $\sim 45$ degrees and they occur in three sub-swarms now offset and uplifted differentially by the ca. 2000 Ma Kapuskasing structure (West and Ernst, 1991). Geothermobarometric analysis indicates that the dykes exposed at the surface today were emplaced at paleodepths of 10 to $21 \mathrm{~km}$ (Percival et al., 1994). A study of dyke geochemistry concluded that their petrogenesis was a two stage process involving lower-crustal fractionation and assimilation of 
plume head-derived melts, followed by later compositional modification in mid-crustal, 15-20 km deep magma chambers (Phinney and Halls, 2001). This contrasts with the Mackenzie dyke swarm, which appears to have been extracted directly from a plume head, and suggests that propagation of the Matachewan dykes may have been confined to the top 20 to $25 \mathrm{~km}$ of crust.

The average width of Matachewan dykes outside of the Kapuskasing zone is 10 to $20 \mathrm{~m}$, but there is a strong tendency for dykes to become fewer in number and thicker moving away from the swarm center (Bates and Halls, 1991; Halls et al., 1994). For example, towards the northern end of the M2 sub-swarm, $>40 \%$ of dykes have widths in the range 25 to $55 \mathrm{~m}$, whereas in the southern part of the same sub-swarm only $\sim 20 \%$ of dykes are wider than $25 \mathrm{~m}$ (Halls et al., 1994). Based on aeromagnetic interpretation by West and Ernst (1991), the mean spacing between Matachewan dykes $~ 500 \mathrm{~km}$ north of the swarm center in all three sub swarms is $4.2 \pm 2.4 \mathrm{~km}$. However, this is likely sampling second- and high-order dykes. Moving out to the distal fringes of the swarm, the spacing between continuous dykes with the strongest magnetic anomalies is 19 to $32 \mathrm{~km}$ in the northern part of the M2 sub-swarm and between 12.4 and $16.5 \mathrm{~km}$ in the northwest part of the M3 sub-swarm. As noted by Halls et al. (1994), there is a correlation between the widest dykes and the strongest magnetic anomalies, hence we consider this to be a reasonable estimate of the spacing between first-generation dykes in the Matachewan swarm. If the interpretation above that these dykes propagated within the mid- to upper crust is correct, then this observation is consistent with the predicted $h \approx H$ relationship. The lower spacing in the western M3 swarm may indicate a slightly shallower source magma chamber than the 
M2 swarm and a correspondingly lower height of dyke propagation within the upper crust.

\section{Conclusions}

Analysis of the work rates associated with driving dyke swarms, coupled with scaling analysis that gives rise to estimates of the dyke pressure, thickness, and length, allows us to search for an optimal dyke spacing. To this point it has been a mystery, from a mechanical perspective, as to why multiple dykes would grow in close, but apparently not too close, proximity to one another, thus forming the morphology described as a dyke swarm. Now we can see that, in fact, the mechanical model for a uniform array of horizontallypropagating blade-like dykes implies that an intermediate spacing, on the order of the height of the dykes themselves, is energetically optimal. What's more, we have found that the optimal spacing depends on the nature of the magma source condition, with the constant pressure source condition giving rise to an optimal spacing of $h \approx H$, while the constant magma influx source condition gives rise to two candidates, one near $h \approx 2.5 \mathrm{H}$ and one near $h \approx 0.3 H$, the former of which tentatively appears as the global minimum based on a coarse analysis.

We have also shown that in the case of the constant pressure source, the total flow rate of magma into the dyke swarm decreases with time. Similarly, for the case of constant influx from the source, the pressure required to propagate the dyke swarm increases with time. Both of these behaviors suggest that at some point the system will prefer to initiate new generations of dykes rather than continuing to propagate only the primary generation. 
Hence we anticipate that the dyke spacing will actually be more dense than what is predicted by the optimal spacing, especially in the vicinity of the source.

Dyke swarms in both Iceland and Canada demonstrate spacing between the thickest dykes, which we interpret to be the first generation of growth and which is the set of dykes to which our model is applicable, that scales with and is of the same order as the dyke height. Hence these comparisons with field data lend preliminary support to our analysis.

\section{Acknowledgement}

Support for AB and XZ has been provided by the Commonwealth Scientific and Industrial Research Organisation (CSIRO) through its Petroleum and Geothermal Research Innovative Science Funds.

\section{References}

Adachi, J.I., Peirce, A.P., 2008. Asymptotic analysis of an elasticity equation for a finger-like hydraulic fracture. J. Elasticity 90, 43-69.

Ayele, A., Keir, D., Ebinger, C., Wright, T.J., Stuart, G.W., Buck, W.R., Jacques, E., Ogubazghi, G., Sholan, J., 2009. September 2005 mega-dike emplacement in the Manda-Harraro nascent oceanic rift (Afar depression). Geophysical Research Letters 36, L20306.

Bai, T., Pollard, D.D., 2000. Fracture spacing in layered rocks: a new explanation based on the stress transition. J. Struct. Geol. 22, 43-57. 
Baragar, W.R.A., Ernst, R.E., Hulbert, L., Peterson, T., 1996. Longitudinal petrochemical variation in the Mackenzie dyke swarm, northwestern Canadian Shield. J. Petrology 37, 317-359.

Bates, M.P., Halls, H.C., 1991. Broad-scale Proterozoic deformation of the central Superior Province revealed by paleomagnetism of the 2.45 Ga Matachewan dyke swarm. Can. J. Earth Sci. 28, 1780-1796.

Ben-Jacob, E., Levine, H., 2001. The artistry of nature. Nature 409, 985-986.

Benthem, J.P., Koiter, W.T., 1973. Asymptotic approximations to crack problems, in: Sih, G.H. (Ed.), Methods of analysis and solutions of crack problems: Recent developments in fracture mechanics; Theory and methods of solving crack problems. Noordhoff International Publishing, Leiden, pp. $131-178$.

Brandsdóttir, B., Einarsson, P., 1979. Seismic activity associated with the September 1977 deflation of the Krafla central volcano in North-Eastern Iceland. J. Volcanol. Geotherm. Res. 6, 197-212.

Bruce, P. M., Huppert, H. H., 1989. Thermal controls of basaltic fissure eruptions. Nature 342, 665-667.

Bunger, A.P., 2013. Analysis of the Power Input Needed to Propagate Multiple Hydraulic Fractures. Int. J. Solids Struct. 50, 1538-1549.

Bunger, A.P., Zhang, X., Jeffrey, R.G., 2012. Parameters effecting the interaction among closely spaced hydraulic fractures. Soc. Pet. Eng. J. 17, $292-306$ 
Burchardt, S., Tanner, D.C., Troll, V.R., Krumbholz, M., Gustafsson, L.E., 2011. Three-dimensional geometry of concentric intrusive sheet swarms in the Geitafell and the Dyrfjöll volcanoes, eastern Iceland. Geochemistry Geophysics Geosystems 12.

Clauset, A., Shalizi, C.R., Newman, M.E.J., 2009. Power-law distribution in empirical data. SIAM Review 51, 661-703.

Detournay, E., 2004. Propagation regimes of fluid-driven fractures in impermeable rocks. Int. J. Geomechanics 4, 1-11.

Duffield, W.A., Christiansen, R.L., Koyanagi, R.Y., Peterson, D.W., 1982. Storage, migration, and eruption of magma at Lilauea volcano, Hawaii, 1971-1972. J. Volcanol. Geotherm. Res. 13, 273-307.

Ernst, R.E., Baragar, W.R.A., 1992. Evidence from magnetic fabric for the flow pattern of magma in the Mackenzie giant radiating dyke swarm. Nature 356, 511-513.

Ernst, R.E., Buchan, K.L., 2001. The use of mafic dike swarms in identifying and locating mantle plumes, in: Ernst, R.E., Buchan, K.L. (Eds.), Mantle Plumes: Their Identification Through Time. Geological Society of America, Boulder, Colorado, pp. 247-265. Special Paper 352.

Ernst, R.E., Grosfils, E.B., Mège, D., 2001. Giant Dike Swarms: Earth, Venus, and Mars. Annu. Rev. Earth Planet. Sci. 29, 489-534.

Ernst, R.E., Head, J.W., Parfitt, E., Grosfils, E., Wilson, L., 1995. Giant radiating dyke swarms on Earth and Venus. Earth and Environmental Science Transactions of the Royal Society of Edinburgh 39, 1-58. 
Fahrig, W.F., 1987. The tectonic settings of continental mafic dyke swarms: failed arm and early passive margin, in: Halls, H.C., Fahrig, W.F. (Eds.), Mafic Dyke Swarms. Geol. Assoc. Can. Spec. Paper 34, pp. 331-348.

Germanovich, L.N., Ring, L.M., Astakhov, D.K., Shlyopobersky, J., Mayerhofer, M.J., 1997. Hydraulic fracture with multiple segments II: Modeling. Int. J. Rock Mech. Min. Sci. 34. Paper 098.

Gudmundsson, A., 1983. Form and dimensions of dykes in eastern Iceland. Tectonophysics 95, 295-307.

Gudmundsson, A., 1995. Infrastructure and mechanics of volcanic systems in Iceland. J. Volcanol. Geotherm. Res. 64, 1-22.

Halls, H.C., Fahrig, W.F. (Eds.), 1987. Mafic Dyke Swarms. Geol. Assoc. Can. Spec. Pap. 34.

Halls, H.C., Palmer, H.C., Bates, M.P., Phinney, W.C., 1994. Constraints of the nature of the Kapuskasing structural zone from the study of Proterozoic dyke swarms. Can. J. Earth Sci. 31, 1182-1196.

Hobbs, D.W., 1967. The formation of tension joints in sedimentary rocks: an explanation. Geological Magazine 104, 550-556.

Hou, G., Kusky, T.M., Want, C., Wang, Y., 2010. Mechanics of the giant radiating Mackenzie dyke swarm: A paleostress field modeling. J. Geophys. Res. 115, B02402.

Jeffrey, R.G., Bunger, A.P., Lecampion, B., Zhang, X., Chen, Z.R., van As, A., Allison, D., Beer, W.D., Dudley, J.W., Siebrits, E., Thiercelin, 
M., Mainguy, M., 2009. Measuring hydraulic fracture growth in naturally fractured rock, in: Proceedings SPE Annual Technical Conference and Exhibition, New Orleans, Louisiana, USA. SPE 124919.

Jin, Z.H., Johnson, S.E., 2008. Magma-driven multiple dike propagation and fracture toughness of crustal rocks. J. Geophys. Res. 113, B03206.

Johnsen, G.V., Björnsson, A., Sigurdsson, S., 1980. Gravity and elevation changes caused by magma movement beneath the Krafla Caldera, Northeast Iceland. J. Geophys. 47, 132-140.

Jolly, R.J.H., Cosgrove, J.W., Dewhurst, D.N., 1998. Thickness and spatial distributions of clastic dykes, northwest Sacramento Valley, California. J. Struct. Geol. 20, 1663-1672.

Jolly, R.J.H., Sanderson, D.J., 1995. Variation in the form and distribution of dykes in the Mull swarm, Scotland. J. Struct. Geol. 17, 1543-1557.

Lecampion, B., Detournay, E., 2007. An implicit algorithm for the propagation of a plane strain hydraulic fracture with fluid lag. Computer Meth. Appl. Mech. Eng 196, 4863-4880.

LeCheminant, A., Heaman, L., 1989. Mackenzie igneous events, Canada: Middle Proterozoic hotspot magmatism associated with ocean opening. Earth Planet. Sci. Lett 96, 38-48.

Lister, J.R., 1990. Buoyancy-driven fluid fracture: similarity solutions for the horizontal and vertical propagation of fluid-filled cracks. J. Fluid Mech. $217,213-239$. 
Lister, J.R., Kerr, R.C., 1991. Fluid-mechanical models of crack propagation and their application to magma transport in dykes. J. Geophys. Res. 96, 10049-10077.

Mériaux, C., Jaupart, C., 1998. Dike propagation through an elastic plate. J. Geophys. Res. 103, 18,295-18,314.

Narr, W., Suppe, J., 1991. Joint spacing in sedimentary rocks. J. Struct. Geol. 11, 1037-1048.

Nordgren, R., 1972. Propagation of vertical hydraulic fractures. J. Pet. Tech. 253, 306-314. (SPE 3009).

Odé, H., 1957. Mechanical analysis of the dike pattern of the Spanish Peaks area, Colorado. Bulletin of the Geological Society of America 68, 567-576.

Olson, J.E., 2004. Predicting fracture swarms - the influence of subcritical crack growth and the crack-tip process zone on joint spacing in rock, in: Cosgrove, J.W., Engelder, T. (Eds.), The initiation, propagation, and arrest of joints and other fractures. Geological Society, London. volume 231, pp. $73-87$.

Olson, J.E., 2008. Multi-fracture propagation modeling: Applications to hydraulic fracturing in shales and tight gas sands, in: Proceedings 42nd US Rock Mechanics Symposium, San Francisco, CA, USA. ARMA 08-327.

Olson, J.E., Dahi-Taleghani, A., 2009. Modeling simultaneous growth of multiple hydraulic fractures and their interaction with natural fractures, in: Proceedings SPE Hydraulic Fracturing Technology Conference and Exhibition, The Woodlands, Texas, USA. SPE 119739. 
Paquet, F., Dauteuil, O., Hallot, E., Moreau, F., 2007. Tectonics and magma dynamics coupling in a dyke swarm of Iceland. Journal of Structural Geology 29, 1477-1493.

Peltier, A., Staudacher, T., Bachèlery, P., 2007. Constraints on magma transfers and structures involved in the 2003 activity at Piton de La Fournaise from displacement data. Journal of Geophysical Research 112, B03207.

Percival, J.A., Palmer, H.C., Barnett, R.L., 1994. Quantitative estimates of emplacement level of postmetamorphic mafic dykes and subsequent erosion magnitude in the southern Kapuskasing uplift. Can. J. Earth Sci. 31, 12181226.

Perkins, T., Kern, L., 1961. Widths of hydraulic fractures. J. Pet. Tech., Trans. AIME 222, 937-949.

Petford, N., Kerr, R. C., Lister, J. R., 1993. Dike transport of granitoid magmas. Geology 21, 845-848.

Phinney, W.C., Halls, H.C., 2001. Petrogenesis of the Early Proterozoic Matachewan dykes swarm, Canada, and implications for magma emplacement and subsequent deformation. Can. J. Earth Sci. 38, 1541-1563.

Roper, S.M., Lister, J.R., 2005. Buoyancy-driven crack propagation from an over-pressured source. J. Fluid Mech. 536, 79-98.

Roussel, N.P., Sharma, M.M., 2011. Optimizing fracture spacing and sequencing in horizontal-well fracturing. SPE Production \& Operations , 173-184SPE 127986. 
Rubin, A.M., Pollard, D.D., 1987. Origin of blade-like dikes in volcanic rift zones. U.S. Geol. Surv. Prof. Pap., 1449-1470.

Sigurdsson, H., 1987. Dyke injection in Iceland: A review, in: Halls, H.C., Fahrig, W.F. (Eds.), Mafic Dyke Swarms, pp. 55-64.

Sneddon, I.N., 1946. The distribution of stress in the neighborhood of a crack in an elastic solid. Proc. Roy. Soc. London A 187, 229-260.

Stott, G.M., Josey, S.D., 2009. Proterozoic mafic (diabase) dikes and other Post-Archean intrusions of northwestern Ontario north of latitude 4930'. Ont. Geol. Surv. Prelim. Map P3606, scale 1:1,000,000.

Swanson, D.A., 1972. Magma supply rate at Kilauea volcano, 1952-1971. Science 175, 169-170.

Taisne, B., Jaupart, C., 2009. Dike propagation through layered rocks. J. Geophys. Res. 114, B09203.

Taisne, B., Tait, S., Jaupart, C., 2011. Conditions for the arrest of a vertical propagating dyke. Bull. Volcanology 73, 191-204.

Thordarson, T., Self, S., 1993. The Laki (Saftár Fires) and Grímsvötn eruptions in 1783-1785. Bull. Volcanology 55, 233-263.

Traversa, P., Pinel, V., Grasso, J.R., 2010. A constant influx model for dike propagation: Implications for magma reservoir dynamics. J. Geophys. Res. 115, B01201. 
Tryggvason, E., 1986. Multiple magma reservoirs in a rift zone volcano: ground deformation and magma transport during the September 1984 eruption of Krafla, Iceland. J. Volcanol. Geotherm. Res. 28, 1-44.

Vermylen, J.P., Zoback, M.D., 2011. Hydraulic fracturing, microseismic magnitudes, and stress evolution in the Barnett Shale, Texas, USA, in: Proceedings SPE Hydraulic Fracturing Technology Conference and Exhibition, The Woodlands, Texas, USA. SPE 140507.

Walker, G.P.L., 1986. Koolau dike complex, Oahu: Intensity and origin of a sheeted-dike complex high in a Hawaiian volcanic edifice. Geology 14, $310-313$

Weng, X., Kresse, O., Cohen, C., Wu, R., Gu, H., 2011. Modeling of hydraulic-fracture-network propagation in a naturally fractured formation. SPE Production \& Operations 26, 368-380.

West, G.F., Ernst, R.E., 1991. Evidence from aeromagnetics on the configuration of Matachewan dykes and the tectonic evolution of the Kapuskasing Structural Zone, Ontario, Canada. Can. J. Earth Sci. 28, 1797-1811.

White, R.S., Drew, J., Martens, H.R., Key, J., Soosalu, H., Jakobsdóttir, S.S., 2011. Dynamics of dyke intrusion in the mid-crust of Iceland. Earth Planet. Sci. Lett. 304, 300-312.

Wright, T.L., Tilling, R.I., 1980. Chemical variation in Kilauea eruption 1971-1974. Am. J. Sci. 280-A, 777-793.

Zhang, X., Jeffrey, R.G., Bunger, A.P., Thiercelin, M., 2011. Initiation and 
810

811

812

813

814

growth of a hydraulic fracture from a circular wellbore. Int. J. Rock Mech. Min. Sci. 48, 984-995.

Zhang, X., Jeffrey, R.G., Thiercelin, M., 2007. Deflection and propagation of fluid-driven fractures at frictional bedding interfaces: A numerical investigation. J. Struct. Geol. 29, 396-410. 


\title{
Analytical Predictions for a Natural Spacing within Dyke Swarms: Supplementary Material
}

\author{
Andrew P. Bunger ${ }^{\mathrm{a}, \mathrm{b}, *}$, Thierry Menand ${ }^{\mathrm{c}, \mathrm{d}, \mathrm{e}}$, Alexander Cruden ${ }^{\mathrm{f}}$, Xi Zhang ${ }^{\mathrm{b}}$, \\ Henry Halls ${ }^{g}$ \\ ${ }^{a}$ Department of Civil and Environmental Engineering, University of Pittsburgh, \\ Pittsburgh, PA, USA \\ ${ }^{b}$ CSIRO Earth Science and Resource Engineering, Melbourne, Australia \\ ${ }^{c}$ Clermont Université, Université Blaise Pascal, Laboratoire Magmas et Volcans, \\ Clermont-Ferrand, France \\ ${ }^{d}$ CNRS, UMR 6524, LMV, Clermont-Ferrand, France \\ ${ }^{e} I R D, R$ 163, LMV, Clermont-Ferrand, France \\ ${ }^{f}$ School of Geosciences, Monash University, Melbourne, Australia \\ ${ }^{g}$ Department of Chemical and Physical Sciences, University of Toronto at Mississauga, \\ Mississauga, Ontario, Canada
}

\section{Near-Field Interaction Stress}

Here we present the asymptotic form of the interaction stress for the 3 closely-spaced limit $h \ll H \ll R$. Proceeding in the same way as Bunger 4 (2012), we begin with the expression for the normal traction $\sigma_{z}$ (compression 5 positive) induced on a plane $z= \pm h$ due to a crack located at $z=0$, $6-H / 2<y<H / 2$ and subjected to an internal pressure $p_{o}$ is given by

7 (Sneddon, 1946)

$$
-\frac{\sigma_{z}}{p_{o}}=\operatorname{Re} Y+\zeta \operatorname{Im} Y^{\prime}
$$

*710 Benedum Hall, 3700 O'Hara Street, Pittsburgh, PA, 15261, USA

Email address: bunger@pitt.edu (Andrew P. Bunger) 
8 where Re and Im indicate the real and imaginary parts, respectively, $Y$ is

9 the Westergaard stress function

$$
Y=\frac{\mathbf{z}}{\sqrt{\mathbf{z}^{2}-1}}-1
$$

and the ' denotes the derivative with respect to the complex coordinate

$$
\mathbf{z}=\eta+\mathrm{i} \zeta
$$

with $\mathrm{i}=\sqrt{-1}$ and where $\eta=2 y / H$ and $\zeta=2 h / H$. Taking the Taylor Series of Eq. (2) for $\zeta \ll 1$ and substituting into Eq. (1) gives

$$
\sigma_{I}=p\left(1-\frac{2 \zeta}{\left(1-\eta^{2}\right)^{3 / 2}}+O(h / H)^{3}\right) .
$$

Considering the stress along $\eta=0$ leads directly to Eq. (3, Main Text). Note that the influence of the $\eta(y)$ dependence of the interaction stress in the near-field case on the opening at the center $w$ is compensated using the variable coefficient $\alpha_{1}$ (Eq. 1, Main Text), which is determined numerically in 2 .

\section{Calculations for Interacting Cracks}

Calculation of the cross sections of multiple interacting cracks was carried out using the MineHF implementation (Zhang et al., 2007) of the displacement discontinuity method (Crouch and Starfield, 1983). Because we consider cross sections of blade-like cracks, the pressure is taken to be uniform (e.g. Nordgren, 1972). We also take the pressure to be equal in each crack in the array. For these calculations, $p_{f}=7 \mathrm{MPa}, \sigma_{o}=6 \mathrm{MPa}, E^{\prime}=52.5$ GPa, $H=2 \mathrm{~m}$, and the spacing $h$ is varied between $20 \mathrm{~m}$ and $0.1 \mathrm{~m}$. Each 
crack was discretized with 80 elements, and numerical experiments with 50 elements confirm mesh insensitivity at this discretization. The crack tip is captured using a square root element and the other elements are linear displacement discontinuities. We use the central crack in an array of $N=13$ cracks in each case we present.

Figure S1 shows that the cracks transition from an elliptical shape when widely-spaced to the closely-spaced case wherein it takes a shape that increases from the central portion to the vicinity of the tip where it rapidly decreases to zero. For the modified Poiseuille equation (Eq. 5, Main Text with $\alpha_{3}=1$ ) we assume a rectangular cross section in the closely-spaced limit.

Figure S2 shows the transition from the elasticity relationship $w=2 H p / E^{\prime}$ when interaction can be neglected to $w \approx 0.35 H\left(p-\sigma_{I}\right) / E^{\prime}$ with $\sigma_{I}$ given by Eq. (3, Main Text) when the cracks are closely spaced. This calculation is the basis for the value of $\alpha_{1}$ in Eq. (1, Main Text).

Figure S3 shows the transition from the area given by an ellipse when widely-spaced to a scenario where the area exceeds by $10 \%$ that which would be obtained from a rectangular crack opening when $H / h=20$. Because the present work is aimed at approximation, we take the area to be equal to $w H$ for the purpose of the continuity equation (Eq. 4, Main Text).

\section{Closely-Spaced Power Factors}

Following Bunger (2012), the rate of work of the interaction stress (shown here for a single blade-like wing in contrast to the reference which considers 


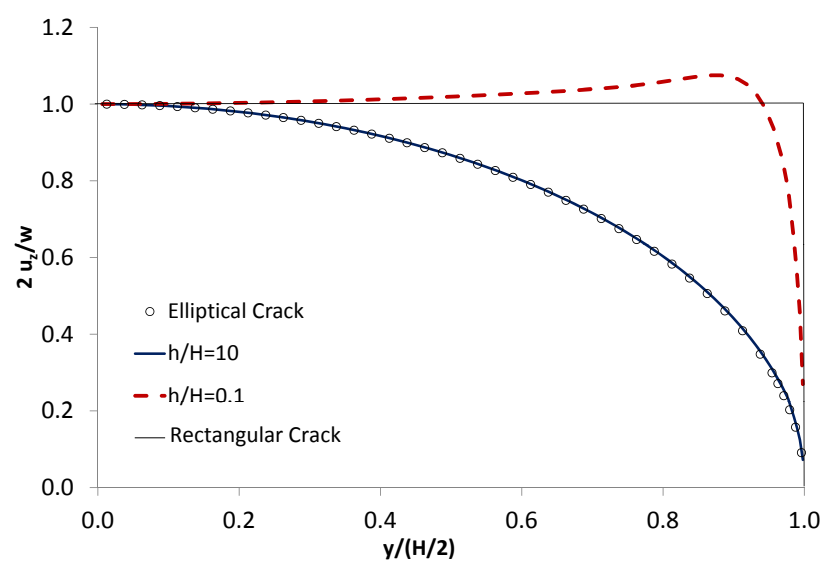

Figure S1: Opening profile for widely-spaced and closely-spaced cracks, where the $y>0$ half of the crack is presented by symmetry and here we have used the central crack in an array of $N=13$. Here $u_{z}(y)$ is the displacement of each crack face and $w=2 u_{z}(0)$.

a hydraulic fracture with two wings) is given by

$$
\dot{W}_{I}=-\frac{\pi}{4} H \int_{0}^{R} \sigma_{I} \frac{\partial w}{\partial t} \mathrm{~d} x .
$$

Substituting Eq. (3, Main Text) for the near-field stress $(h \ll H)$ and the 51 scaling from Eq. (17, Main Text) leads to

$$
\dot{W}_{I}=-\frac{H L P X}{t} \frac{\pi}{4} \gamma \int_{0}^{1} \frac{t}{X} \frac{\partial \Omega}{\partial t} \Pi\left(1-\frac{4 h}{H}+O(h / H)^{2}\right) \mathrm{d} \rho .
$$

${ }_{52}$ Hence it is clear that $\dot{W}_{I}$ is approximated according to Eq. (16, Main Text) provided that the characteristic quantities $\{L, X, P\}$ are chosen such that ${ }_{54}\{\gamma, \Omega, \Pi\}$ are all $O(1)$.

$55 \quad$ Similarly, following Bunger (2012), the expression for the fluid dissipation 


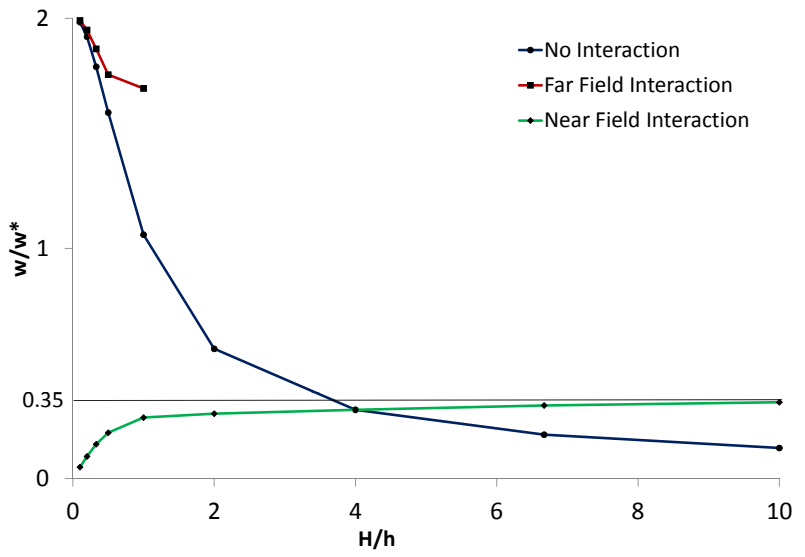

Figure S2: Relationship between $w$ and $w^{*}$ determined from elasticity as a function of $H / h$, where for "no interaction" $w^{*}=H p / E^{\prime}$ and $w^{*}=H\left(p-\sigma_{I}\right) / E^{\prime}$ otherwise, with $\sigma_{I}$ from Eq. (2, Main Text) for the "far field interaction" $(h / H \gg 1)$ case and from Eq. (3, Main Text) for the "near field interaction" $(h / H \ll 1)$ case. 


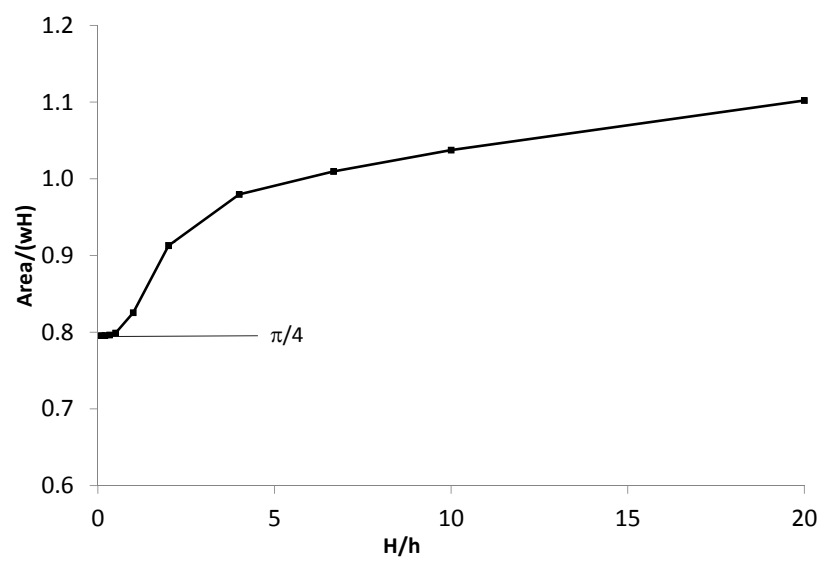

Figure S3: Dependence of the crack opening area normalized by $w H$ on $H / h$ showing tendency to $\pi / 4$ for the elliptical profile for widely-spaced cracks and to tend to a value that is a bit greater than 1 for closely-spaced cracks.

56 is given by

$$
D_{f}=\frac{3 \pi}{32} \frac{H}{\mu^{\prime}} \int_{0}^{R} w^{3}\left(\frac{\partial p}{\partial x}+\frac{\partial \sigma_{I}}{\partial x}\right)^{2} \mathrm{~d} x .
$$

${ }_{57}$ Again, substituting Eq. (3, Main Text) for the near-field stress $(h \ll H)$ and 58 the scaling from Eq. (17, Main Text) leads to

$$
D_{f}=\frac{H X^{3} P^{2}}{L \mu^{\prime}} \frac{3 \pi}{8 \gamma} \int_{0}^{1} \Omega^{3}\left(\frac{\partial \Pi}{\partial \rho}\right)^{2}\left(1-\frac{2 h}{H}+O(h / H)^{2}\right)^{2} \mathrm{~d} \rho .
$$

59 And so it is again clear that $D_{f}$ is approximated according to Eq. (16, Main ${ }_{60}$ Text) provided that the characteristic quantities $\{L, X, P\}$ are chosen such 61 that $\{\gamma, \Omega, \Pi\}$ are all $O(1)$. 


\section{References}

Bunger, A.P., 2012. Analysis of the Power Input Needed to Propagate Multiple Hydraulic Fractures. Technical Report EP128743. CSIRO Earth Science and Resource Engineering. Melbourne, Australia. Submitted to International Journal of Solids and Structures.

Crouch, S., Starfield, A., 1983. Boundary Element Methods in Solid Mechanics. Unwin Hyman, London.

Nordgren, R., 1972. Propagation of vertical hydraulic fractures. J. Pet. Tech. 253, 306-314. (SPE 3009).

Sneddon, I.N., 1946. The distribution of stress in the neighborhood of a crack in an elastic solid. Proc. Roy. Soc. London A 187, 229-260.

Zhang, X., Jeffrey, R.G., Thiercelin, M., 2007. Deflection and propagation of fluid-driven fractures at frictional bedding interfaces: A numerical investigation. J. Struct. Geol. 29, 396-410. 